3. Ceneviva G, Paschall AJ, Maffei F, Carcillo AJ. Hemodynamic support in fluid-refractory pediatric septic shock. Pediatrics 1998;102(20):19-32.

4. Kleinman EM. Clinical practice parameters for pediatric and neonatal septic shock; to have or to have not? Crit Care Med 2002;0(6):1-3.

5. Holmes LC, Patel MB, Russel A. Physiology of vassopresin relevant to management of septic shock. Chest 2001;120(3):1-20.

6. Bone RC, Fisher CJ Jr, Clemmer TP, Slotman GJ, Metz CA, Balk RA. A controlled clinical trial of high-dose methylprednisole in the treatment of severe sepsis and septic shock. N Engl J Med 1987;317:653-8.
7. Tabbut S. Heart failure in pediatric septic shock; Utilizing inotropic support. Crit Care Med 2001;29(10):1-11.

8. Sibbald JW, Vincent LJ. Clinical trials for the treatment of sepsis. Update in Intensive Care and Emergency Medicine. Vol. 19. Berlim, Germany: Springer-Verlag; 1995.

Endereço para correspondência:

Dr. Roberto Sapolnik

Rua do Barro Vermelho, 299/402 - Rio Vermelho

41940-340 - Salvador, BA

E-mail: sapolnik@uol.com.br

\title{
Perfil etiológico das meningites bacterianas na infância - uma realidade transitória
}

\author{
Etiological profile of bacterial meningitis in children - a transitory reality
}

\author{
Regina Célia de Menezes Succi*
}

Os primeiros dois enos de vida são aqueles em que ocorre a maioria dos casos de meningites bacterianas. Conhecer o perfil etiológico dessa doença em uma cidade, estado, região ou país, antes de ser apenas uma simples curiosidade médica, tem valor fundamental na tomada de decisões terapêuticas e profiláticas. Os riscos potenciais de determinar morte ou seqüelas definitivas tornam as meningites bacterianas objeto de temor não só entre profissionais, mas entre os familiares das crianças atingidas.

Vários agentes bacterianos podem causar meningites na infância, mas três bactérias são responsáveis por mais de 90\% das meningites com agente etiológico identificado em nosso meio: Neisseria meningitidis (meningococo), Haemophilus influenzae tipo b (Hib) e Streptococcus pneumoniae (pneumococo) ${ }^{1-4}$.

A letalidade nas meningites bacterianas pode atingir níveis próximos a $30 \%$, dependendo da faixa etária acometida e do agente etiológico. Para diminuir a letalidade e os riscos de seqüelas graves, o início do tratamento antimicrobiano deve ser estabelecido precoce e adequadamente. A escolha do antimicrobiano depende da sua atividade para o agente infeccioso, da sua penetração liquórica e do conhe-

* Prof ${ }^{a}$ Adjunta de Pediatria da Universidade Federal de São Paulo e Presidente do Departamento de Infectologia da SBP. cimento do perfil etiológico das meningites numa determinada região. A emergência de cepas bacterianas resistentes aos antimicrobianos comumente utilizados e as dificuldades no isolamento dos agentes causadores aumentam a preocupação com as meningites bacterianas.

Como demonstraram o Dr. Mantese e colaboradores, em artigo deste número do Jornal de Pediatria $^{2}$, o uso prévio de antimicrobianos é prática comum em nosso meio. Esse uso indiscriminado dos antimicrobianos, além de não contribuir para a prevenção de danos, dificulta o diagnóstico etiológico e pode ser fator determinante de pior prognóstico.

O perfil etiológico das meningites bacterianas mudou significantemente nos últimos anos, e a intervenção mais eficaz nessa mudança foi a introdução da vacina conjugada contra Haemophilus influenzae tipo b (Hib), que está disponível no Brasil, para crianças até dois anos de idade, a partir do segundo semestre de $1999^{5}$. A vacina conjugada contra Hib produz imunidade duradoura e interfere no estado de portador, e como conseqüência, nos países onde se instituiu a vacina aplicada na rotina com ampla cobertura, a infecção por essa bactéria apresentou significante redução da incidência ${ }^{6,7}$. No Brasil, o número de casos de meningites por Hib caiu de 1.731 no ano de 1998 para 577 no ano de $2000^{8}$, e a diminuição da incidência da doença causada por Hib após a introdução da vacina, em vários estados, foi eviden- 
$\mathrm{te}^{3,4}$. No estado de São Paulo, a prevalência de meningite por Hib variou de $13,16 \%$ (sobre todas as etiologias de meningite) em 1994, para 3,81\%, em $2001^{9}$.

A utilização de novas vacinas como as vacinas conjugadas para pneumococo e para meningococo $\mathrm{C}$ devem no futuro modificar ainda mais o perfil etiológico das meningites bacterianas. $O$ pediatra deve estar atento para a realidade local e possivelmente transitória do perfil etiológico das doenças infecciosas e da possibilidade de utilizar meios preventivos que têm ação muito mais duradoura e eficaz no controle das doenças.

\section{Referências bibliográficas}

1. Farhat CK, Ribeiro AF, Musa SCF, Succi RCM, Marques SR, Carvalho ES. Meningites na Infância - estudo de 777 casos - 1 . Etiologia. XXXI Congresso Brasileiro de Pediatria. Tema $\mathrm{n}^{\circ}$ 390. Rev Pediatr Ceará 2000; 1(supl.1):215.

2. Mantese OC, Hirano J, Santos IC, Silva VM, Castro E. Perfil etiológico das meningites bacterianas em crianças. J Pediatr (Rio J) 2002;78(6):467-74.
3. Romanelli RMC, Araújo CA, Dias MW, Boucinhas F, Carvalho IR, Martins NRL, et al. Etiologia e evolução das meningites bacterianas em centro de pediatria. J Pediatr (Rio J) 2002; 78: 24-30.

4. Takemi NS, Andrade SM Meningite por Haemophilus influenzae tipo b em cidades do Estado do Paraná. J Pediatr (Rio J) 2001;77:287-92.

5. FUNASA - Programa Nacional de Imunizações. Disponível em: http://www.funasa.gov.br/imu/imu01.htm

6. Forleo-Neto E, Oliveira CF, Maluf EMCP, Bataglin C, Araújo JMR, Kunz Jr. LF, et al. Decrease point prevalence of Haemophilus influenza type b (Hib) oropharyngeal colonization by mass immunization of Brazilian children less than 5 years old with Hib polyribosylribitol phosphate polyssacharide-tetanus toxoid conjugate vaccine in combination with diphteria-tetanus toxoids- pertussis vaccine. J Infect Dis 1999;180(4):1153-8.

7. CDC. Progress toward elimination of Haemophilus influenzae type $b$ disease among infants and children - United States, 19871997. MMWR 1998;47:993-8.

8. FUNASA. Casos confirmados, segundo o período de diagnóstico e local de residência, por UF. Brasil, 1980-2001. Em: http:// www.funasa.gov.br/epi/pdfs

9. SVE-DDT respiratória-CVE/SINAM (1989-2001). Meningites determinadas segundo os principais agentes etiológicos - Estado de São Paulo 1989 a 2001. Disponível em: http:// www.cve.Saude.sp.gov.br/htm/resp/meni_detetio8901.htm

\title{
Tubos de ventilação
}

\author{
Tympanostomy tubes
}

Manoel de Nóbrega*

$\mathbf{N}_{\mathrm{o}}$ ano ao pediatra por doenças do ouvido médio e/ou disfunção da tuba auditiva atinge a cifra de 1.394 .000 consultas/ano. Os gastos com medicamentos são significativamente mais caros no tratamento da otite média recorrente (US\$ 124,64), quando comparados a um tratamento inicial (US\$ 107,81). São gastos anualmente três e meio bilhões de dólares somente para o tratamento clínico das doenças da orelha média ${ }^{1}$.

Como conseqüência, mais de 1 milhão de crianças são submetidas anualmente à colocação de tubo de ventilação (TV), constituindo mais de 2 milhões de TV colocados por ano ${ }^{2}$.

\footnotetext{
* Mestre em Otorrinolaringologia pela UNIFESP-EPM.
}

De acordo com Saffer et al. ${ }^{3}$, a colocação de TV é benéfica para pacientes com hipoacusia bilateral, decorrente de otite média crônica secretora, considerando-se a história natural da doença, os riscos de resistência bacteriana, os benefícios comprovados e a técnica simples de colocação. Estes TVs serão indicados sempre que o curso da otite média crônica secretora, acompanhada ativamente por três a seis meses, evoluir desfavoravelmente naquelas crianças de baixo risco.

Saffer et al. ${ }^{3}$ destacam ainda que não se deve esquecer que um único procedimento cirúrgico não soluciona o problema do paciente em tratamento, uma vez que a resolução para a otite média crônica secretora está baseada no crescimento da criança com o desenvolvimento da tuba auditiva e da sua imunidade de forma adequada. 